\title{
Measurement and Analysis of Oxygen/Nitrogen/5A-Zeolite Adsorption Equilibria for Air Separation
}

Orhan Talu

Cleveland State University

Follow this.and additional works at: https://engagedscholarship.csuohio.edu/encbe_facpub Jianmin Li

vedathof Sheteldraivensityal and Biomolecular Engineering Commons, and the Membrane Science

Rompons

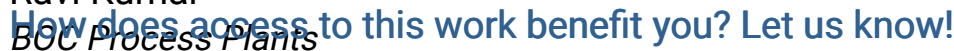

Publisher's Statement

Raft ICE:Mathias the author's version of a work that was accepted for publication in Gas Air Products \& Chemicals, Inc.

Separation and Purification. Changes resulting from the publishing process, such as peer review,

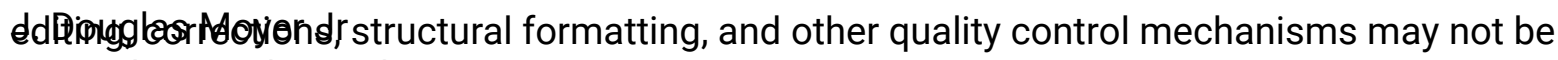

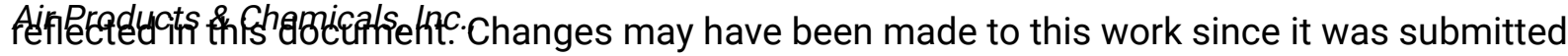
for publication. A definitive version was subsequently published in Gas Separation and

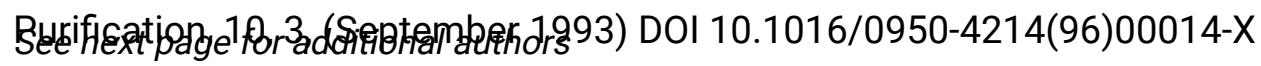

\section{Original Citation}

Talu, O., Jianmin, L., Kumar, R., Mathias, P. M., Moyer Jr, J. D., , \& Schork, J. M. (1996). Measurement and analysis of oxygen/nitrogen/5A-zeolite adsorption equilibria for air separation. Gas Separation \& Purification, 10(3), 149-159.

\section{Repository Citation}

Talu, Orhan; Li, Jianmin; Kumar, Ravi; Mathias, Paul M.; Moyer, J. Douglas Jr; and Schork, Joan M., "Measurement and Analysis of Oxygen/Nitrogen/5A-Zeolite Adsorption Equilibria for Air Separation" (1996). Chemical \& Biomedical Engineering Faculty Publications. 54.

https://engagedscholarship.csuohio.edu/encbe_facpub/54

This Article is brought to you for free and open access by the Chemical \& Biomedical Engineering Department at EngagedScholarship@CSU. It has been accepted for inclusion in Chemical \& Biomedical Engineering Faculty Publications by an authorized administrator of EngagedScholarship@CSU. For more information, please contact library.es@csuohio.edu. 


\section{Authors}

Orhan Talu, Jianmin Li, Ravi Kumar, Paul M. Mathias, J. Douglas Moyer Jr, and Joan M. Schork 


\title{
Measurement and analysis of oxygen/nitrogen/ 5A-zeolite adsorption equilibria for air separation
}

\author{
Orhan Talu, ${ }^{b}$ Jianmin Li, ${ }^{b} \ddagger$ Ravi Kumar, ${ }^{c}$ Paul M. Mathias, ${ }^{a *}$ \\ J. Douglas Moyer, Jra and Joan M. Schork ${ }^{a}$
}

${ }^{a}$ Air Products and Chemicals, Inc., 7201 Hamilton Boulevard, Allentown, PA 18195-1501, USA

${ }^{b}$ Department of Chemical Engineering, Cleveland State University, Cleveland, $\mathrm{OH} 44115$, USA

${ }^{c}$ BOC Process Plants, 460 Mountain Avenue, Murray Hill, NJ 07974, USA

\begin{abstract}
Multicomponent adsorption equilibrium data are essential for the reliable design of processes and equipment for gas separation by adsorption. We discuss techniques for the measurement and analysis of multicomponent adsorption equilibrium data, and present a comprehensive set of equilibrium data for the adsorption of oxygen and nitrogen on 5A-zeolite.
\end{abstract}

Keywords: pressure swing adsorption; multicomponent adsorption equilibria; thermodynamic consistency; ideal adsorbed solution theory

\begin{tabular}{|c|c|c|c|}
\hline \multicolumn{2}{|c|}{ Nomenclature } & $V$ & Total volume, Equations (1) and (2) $\left(\mathrm{m}^{3}\right)$ \\
\hline$B$ & Second virial coefficient, Equation (3) & $x_{i}$ & $\begin{array}{l}\text { Adsorbed phase mole fraction of } \\
\text { component } i\end{array}$ \\
\hline C & $\begin{array}{l}(\mathrm{kg} / \mathrm{mol}) \\
\text { Third virial coefficient, Equation (3) }\end{array}$ & $y_{i}$ & Gas phase mole fraction of component $i$ \\
\hline$D$ & $\begin{array}{l}\left((\mathrm{kg} / \mathrm{mol})^{2}\right) \\
\text { Fourth virial coefficient, Equation (3) }\end{array}$ & \multicolumn{2}{|c|}{ Greek symbols } \\
\hline$G^{e x}$ & $\begin{array}{l}\left((\mathrm{kg} / \mathrm{mol})^{3}\right) \\
\text { Excess Gibbs free energy, Equation }(9)\end{array}$ & $\alpha_{i j}$ & $\begin{array}{l}\text { Adsorption selectivity of component } i \text { over } \\
\text { component } i \text {. Equation }(6)\end{array}$ \\
\hline$K$ & $\begin{array}{l}(\mathrm{J} / \mathrm{kmol}) \\
\text { First virial coefficient Equation }(3)\end{array}$ & $\Delta n_{i}$ & Change in number of moles of component $i$, \\
\hline$n$ & Adsorption loading $(\mathrm{mol} / \mathrm{kg})$ & $\gamma$ & Adsorbed phase activity coefficient, \\
\hline$P$ & Pressure $(\mathrm{kPa})$ & & Equation (8) \\
\hline$P_{i}^{0}$ & $\begin{array}{l}\text { Surface pressure of component } i \\
\text { Equation }(8)(\mathrm{kPa})\end{array}$ & $\varphi_{i}$ & $\begin{array}{l}\text { Gas phase fugacity coefficient of } \\
\text { component } i \text { at specified } T, P, y\end{array}$ \\
\hline$R$ & Gas constant $(\mathrm{J} / \mathrm{kmol} \mathrm{K})$ & $\phi_{i}^{0}$ & Gas phase fugacity coefficient of pure gas $i$ \\
\hline$T$ & Temperature $(\mathrm{K})$ & & at specified $T, P_{i}^{0}$, Equation ( 8 ) \\
\hline$t$ & Time (s) & $\pi A / R T$ & Dimensionless spreading pressure, \\
\hline$v$ & Molar volume $\left(\mathrm{m}^{3} / \mathrm{kmol}\right)$ & & Equation (7) \\
\hline
\end{tabular}

\section{Introduction}

Bulk gas separation by Pressure Swing Adsorption (PSA) (including Vacuum Swing Adsorption (VSA)) has been practiced commercially for over 30 years and now represents a major unit operation in the chemical industry ${ }^{1,2}$. Oxygen production from air is one of its major applications ${ }^{1}$. Commercial PSA/VSA oxygen generators range in size from personal units for home medical use, producing a few liters/min, to multi-train industrial units providing 120 tons/day of contained oxygen. 
PSA/VSA technology is an active area of research with the continuing introduction of new adsorbents and new process cycles. At the present time it is not feasible to design new systems based entirely on numerical simulation results. Simulators are used extensively, however, for screening cycles and adsorbents and for scalingup experimental data. Hartzog and Sircar $^{3}$ have shown that the accuracy of simulator results depends heavily upon the accuracy of the multicomponent equilibrium data input, especially when stringent product specifications are imposed ${ }^{3}$. They have concluded that the representation of the multicomponent adsorption equilibrium must be accurate to within $2 \%$ in order to obtain accurate simulation results. It is important that the data be accurately represented over the entire temperature, pressure and composition ranges of the cycle being simulated.

Taking a step back from the accurate representation of multicomponent equilibria, one must first obtain highly accurate data. Measurement of multicomponent adsorption equilibria is complicated and time consuming. The data usually have less accuracy than other phase equilibrium measurements, mainly because the adsorbed phase cannot be measured directly and therefore must be calculated from changes in the properties of the fluid phase. There are several experimental techiques for the measurement of multicomponent adsorption equilibria, but all suffer from a common problem: a large uncertainty in the measured loading of the less strongly adsorbed component.

Two multicomponent experimental techniques were implemented and compared in the research reported here. The system chosen for demonstration was oxygen/ nitrogen/5A-zeolite. Some multicomponent equilibrium data for this system have been reported in the literature $^{4-6}$. The goal of our work was to investigate the procedures necessary to obtain a complete set of accurate multicomponent adsorption data. Toward this aim: 1) extensive pure-component data were collected; 2) multicomponent data were collected in two different laboratories using two different techniques; 3) the pure and multicomponent data were collected at two temperatures and over wide ranges of composition and pressure, including high pressures; and 4) thermodynamic consistency tests were performed on all the data.

The purpose of this paper is to analyze techniques for measuring multicomponent adsorption equilibria, present useful methods for evaluating the resulting data, describe the trends of multicomponent adsorption equilibria, and finally, make available an evaluated set of adsorption equilibrium data for use in the development and testing of adsorption equilibrium models.

\section{Experimental techniques}

Commercial grade 5A-zeolite manufactured by the Tosoh Corporation (A-5 SA, PSA Air Separation) was used in all experiments. All samples were from the same lot of $8 / 10$ mesh beads. The samples were regenerated by heating to $400^{\circ} \mathrm{C}$ at $1^{\circ} \mathrm{C} / \mathrm{min}$ under vacuum. All gases were ultra-high purity.

Pure-component isotherm data were collected using both standard gravimetric and volumetric techniques. Low pressure $(0-101 \mathrm{kPa})$, pure-component data were collected on a Micromeritics ASAP 2000 automated volumetric adsorption apparatus. High pressure (50$1800 \mathrm{kPa}$ ), pure-component data were collected on a high pressure micro balance and a high pressure volumetric adsorption apparatus.

Binary measurements were performed at two different laboratories using two different techniques: a oncethrough, open system technique and a recirculating closed system technique. The amount of zeolite in each system was carefully chosen to minimize errors due to instrument limitations (e.g. pressure transducers). Purecomponent data and the ideal adsorbed solution theory (IAST) $^{7}$ were used to size the systems. Dead volumes in both systems were minimized to increase accuracy.

\section{Open system apparatus}

In the open system technique a flow of a constant composition feed gas passes through the adsorbent bed at a controlled temperature and pressure. The exit flow rate and composition are recorded as functions of time. Using these data and the void volume of the adsorbent bed, the amount adsorbed and its composition can be calculated.

The major components of the open system used are illustrated in Figure 1. The column void volume was $57.4 \pm 0.1 \mathrm{cc}$, measured by both mercury displacement and helium expansion. The sample size was $18.8869 \pm 0.0003 \mathrm{~g}$. The feed composition was controlled by the mass flow controllers. The composition of the feed gas was confirmed by GC analysis with the gas flowing through the bypass. The column temperature was controlled by an external water bath. The inlet gas temperature was equilibrated with the bath using a heat

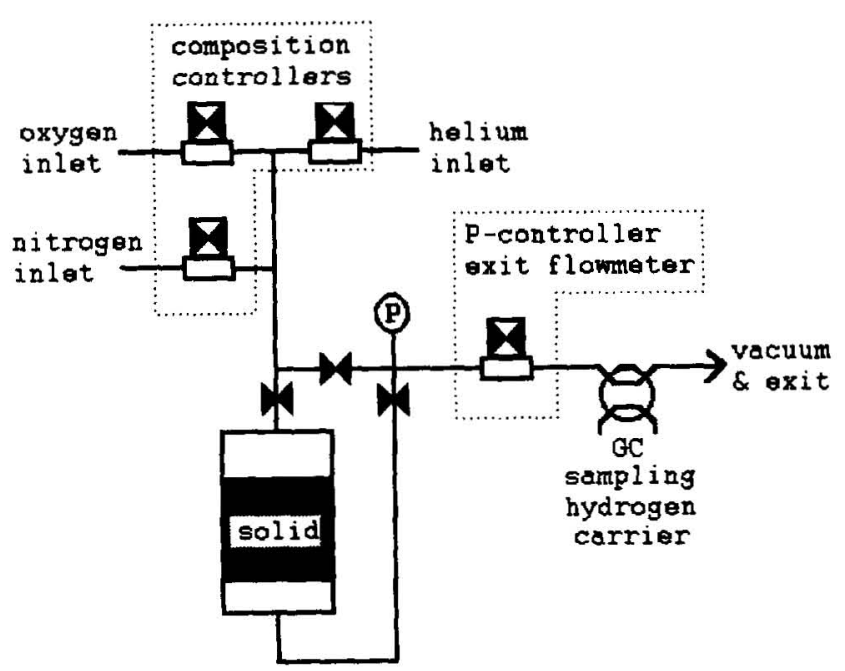

Figure 1 Schematic diagram of open system for measurement of multicomponent adsorption equilibrium 
exchange coil of appropriate size. Temperatures were measured by a thermocouple, with an accuracy of $\pm 0.1^{\circ} \mathrm{C}$, placed at the center of the adsorbent column. The pressure was controlled by the outlet mass flow controller (M4 in Figure 1). Pressures were measured with two different pressure transducers to maximize accuracy: $0-1035 \pm 3 \mathrm{kPa}$ and $0-102 \pm 0.3 \mathrm{kPa}$. The exit gas composition was measured by rapid sampling to a GC equipped with a thermal conductivity detector. Hydrogen carrier gas was used in the GC, since helium was used as a diluent for experiments in which a subatmospheric partial pressure of oxygen plus nitrogen was desired. The accuracy of the composition measurements was \pm 0.001 mole fraction.

\section{Closed system apparatus}

In the closed system technique a gas mixture of known initial composition is constantly circulated over the adsorbent bed in a closed loop. The system is illustrated in Figure 2. The loop volumes in the adsorption section were accurately measured to within $0.1 \mathrm{cc}$ by both mercury displacement and helium expansion. The sample loop and adsorbent bed were controlled to within $\pm 0.1^{\circ} \mathrm{C}$ using external water baths. The gas mixture was prepared and characterized in the feed section. A GC using helium carrier gas and equipped with a thermal conductivity detector was used for all gas analyses. Gas compositions were measured with an accuracy of \pm 0.001 mole fraction. At the start of an experiment, a portion of the gas in the feed section was introduced into the circulation loop while the adsorbent bed was isolated. A pressure measurement was taken using a $0-667 \pm 1 \mathrm{kPa}$ MKS pressure transducer and the initial moles of each component present in the loop were calculated. The gas mixture was then circulated through the adsorbent bed in the closed loop over an extended period of $3 \mathrm{~h}$; this was determined to be adequate to reach equilibrium since previous experiments had determined that equilibrium was reached within $1 \mathrm{~h}$. Recirculation was then stopped and the final pressure measured. Finally, the adsorbent bed was isolated and the gas in the closed loop analyzed by GC. Given these data, the amount and composition of the adsorbed phase could be calculated.

\section{Open system - analysis}

The primary advantage of the open system is the ability of the researcher to control the gas phase properties (pressure and composition) at equilibrium. A gas mixture of the desired final composition is passed over the adsorbent bed until equilibrium is reached. The open system material balance can be arranged to give the partial amount adsorbed of component $i$.

$\Delta n_{i}=\int_{0}^{t}\left(n_{i, \text { in }}-n_{i, \text { out }}\right) \mathrm{d} t-\left[\left.\frac{V_{y_{i}}}{v}\right|_{\text {initial }}-\left.\frac{V_{y_{i}}}{v}\right|_{\text {final }}\right]$

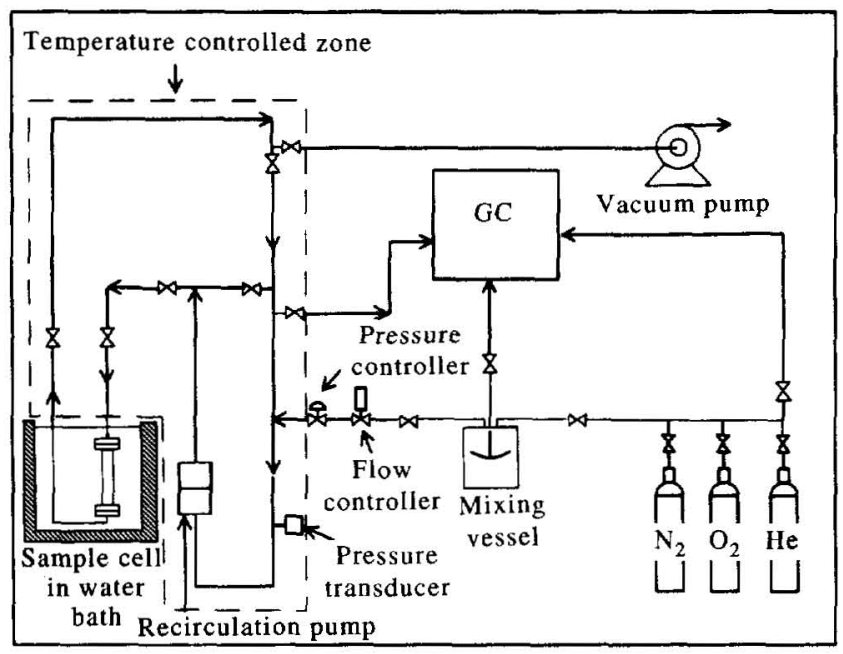

Figure 2 Schematic diagram of closed system for measurement of multicomponent adsorption equilibrium
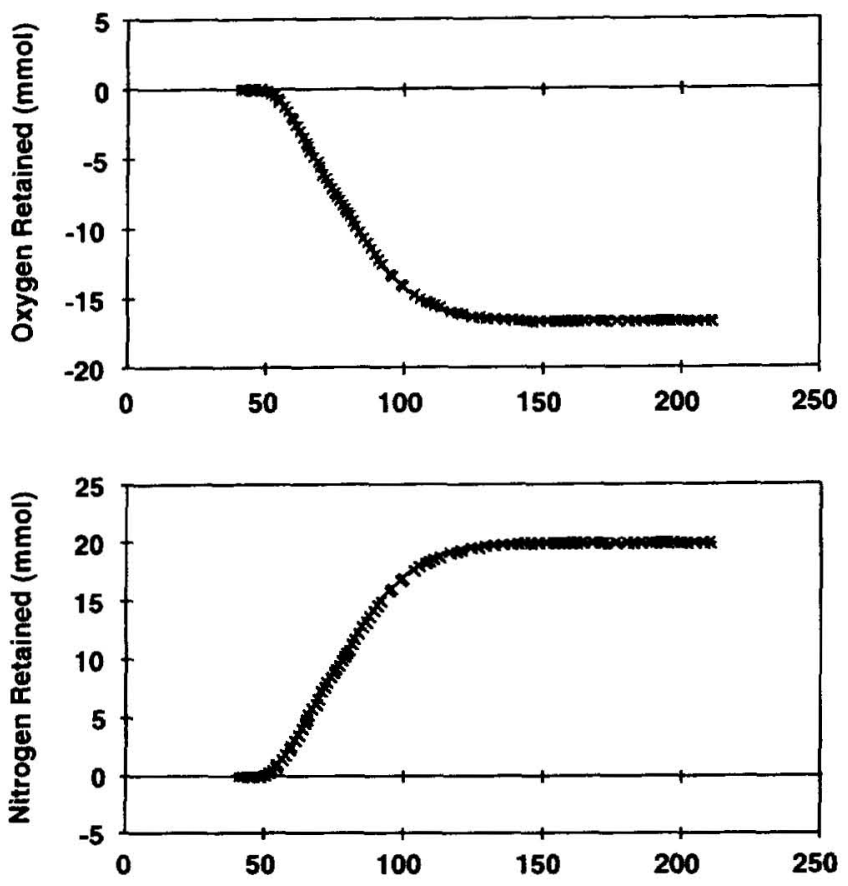

Figure 3 Typical time trace for amounts retained in an open system experiment in which oxygen is desorbed and nitrogen is adsorbed

The first term is the difference between inlet and outlet molar flows, or the amount of species retained in the system. The second term is the correction for gas phase accumulation (or depletion) in the void space. Figure 3 shows a typical time trace for amounts retained for an experiment in which oxygen is desorbed and nitrogen is adsorbed. Both traces end with flat lines, indicating that equilibrium has been established between the gas mixture and the adsorbent. The main disadvantage of the technique is the relatively poor accuracy. The experimental error can reach $10-15 \%$ primarily due to the uncertainty in the measurement of the exit flow rate. This measurement is very difficult because most 
mass flow meters respond to composition as well as flow rate changes. In order to minimize this effect, we calibrated the flow meters for changes in composition. The inevitable variation in the total measured exit flow rate, however, has a pronounced effect on the accuracy.

We used an experimental design in this work to continuously check the accuracy of results for the open system. It is based on the simple thermodynamic principle that the adsorbed phase properties do not depend on the path used to approach equilibrium. Experiments were performed in sets of several runs without regenerating the adsorbent between runs. Each set started and ended at the pure component ends of the phase diagram - points that could be verified on more established single component isotherm equipment (e.g. gravimetric or volumetric adsorption analyzers). Theoretically, the integration of any surface property over an entire set of experimental runs (the addition of the partial amounts adsorbed for each step or run) must equal the difference in the adsorbed phase properties at the two pure-component endpoints; this follows because the surface properties are state functions. Adsorption reversibility is also checked with this approach since the partial pressures are varied without increasing the temperature. The departure from a perfect match is used to assess accuracy. An acceptable match with purecomponent data verifies the accuracy of the endpoints, which indicates that the intermediate points are likely to be accurate. The entire set of data is questionable if the match is unacceptable.

Results for one set of experiments are summarized in Table 1 . The total oxygen material balance is closed to within $0.007 \mathrm{~mol} / \mathrm{kg}$, or a mere $0.6 \%$ of the maximum oxygen amount $(1.251 \mathrm{~mol} / \mathrm{kg})$ adsorbed during the complete set of experiments. This is exceptional accuracy for binary adsorption measurements using the open system technique. The data in Table $l$ are for the worst set measured in this study. The accuracies of the remaining eight sets of data measured and reported in this paper are better than that shown in Table 1.

\section{Closed system - analysis}

The primary advantage of the closed system is the simplicity of the apparatus and operating procedures. It is only necessary to measure the cell free volume, the starting gas composition, pressure, and temperature, and the final gas composition, pressure, and temperature. The inaccuracies associated with flow measurement are avoided.

$\Delta n_{i}=\left.\frac{V_{y_{i}}}{v}\right|_{\text {initial }}-\left.\frac{V_{y_{i}}}{v}\right|_{\text {final }}$

This method is similar to traditional single component volumetric methods, with gas phase composition being the only added measurement. The main disadvantage of the technique is the inability to control the final gas phase properties (composition and pressure) at equilibrium. Even though the necessary charge amount of each component for a set of target equilibrium conditions can be estimated using a predictive multicomponent adsorption model such as IAST, the final conditions can never be exactly controlled and will be different from the target values. In fact, the measurements would be redundant if models such as IAST were capable of accurately predicting equilibrium!

In general, the closed system approach has better accuracy than the open system technique. The gas phase densities were calculated by the virial equation ${ }^{8}$, which is accurate to better than $0.1 \%$ for the conditions of interest. Based upon reproducibility of the results, the uncertainty of the technique is typically $5 \%$ or $0.002 \mathrm{~mol} / \mathrm{kg}$, whichever is larger, for the partial loadings. The accuracy check explained above for the open system technique is not possible in the closed system. The pure-component endpoints cannot be reached in the closed system-an infinite number of pure-component additions are necessary to move a mixture equilibrium point to a pure-component point. Therefore, reproducibility and agreement with measurements made by a different technique are the only indicators of the accuracy of the data.

\section{Experimental data}

Equilibrium isotherms for pure nitrogen and oxygen were measured by the techniques described above. Measurements were carried out at two temperatures, $23^{\circ} \mathrm{C}$ and $45^{\circ} \mathrm{C}$, and pressures from 10 to $1800 \mathrm{kPa}$. Very low pressure data are needed to obtain accurate measurement of the Henry's law slope. High pressure data are necessary for accurate calculation of the spreading pressure of the weakly adsorbed component $\left(\mathrm{O}_{2}\right)$. Both of these are required in order to use IAST for

Table 1 Example of closure of material balance for open system (bed initially activated; no activation between steps)

\begin{tabular}{|c|c|c|c|c|c|c|c|}
\hline \multirow[b]{2}{*}{ Step } & \multirow[b]{2}{*}{$P(\mathrm{kPa})$} & \multirow[b]{2}{*}{$y\left(\mathrm{O}_{2}\right)$} & \multirow[b]{2}{*}{$T\left({ }^{\circ} \mathrm{C}\right)$} & \multicolumn{2}{|c|}{ Moles retained $(\mathrm{kg})$} & \multicolumn{2}{|c|}{ Moles adsorbed $(\mathrm{kg})$} \\
\hline & & & & Oxygen & Nitrogen & Oxygen & Nitrogen \\
\hline 1 & 910.2 & 1.0 & 23.3 & 1.2509 & 0.0 & 1.2509 & 0.0 \\
\hline 2 & 909.5 & 0.1936 & 44.6 & -1.1066 & 1.2744 & 0.1443 & 1.2744 \\
\hline 3 & 916.4 & 0.0 & 23.4 & -0.1508 & 0.6920 & -0.0065 & 1.9664 \\
\hline
\end{tabular}


Table 2 Pure-gas adsorption of nitrogen on Tosoh SA-500

\begin{tabular}{|rrrrr|}
\hline \multicolumn{2}{|c}{$T=23^{\circ} \mathrm{C}$} & & \multicolumn{2}{c|}{$T=45^{\circ} \mathrm{C}$} \\
\cline { 1 - 2 } \cline { 5 - 5 } $\begin{array}{c}\text { Pressure } \\
(\mathrm{kPa})\end{array}$ & $\begin{array}{c}\text { Loading } \\
(\mathrm{mol} / \mathrm{kg})\end{array}$ & & $\begin{array}{c}\text { Pressure } \\
(\mathrm{kPa})\end{array}$ & $\begin{array}{c}\text { Loading } \\
(\mathrm{mol} / \mathrm{kg})\end{array}$ \\
\hline 8.6 & 0.0894 & & 12.0 & 0.0669 \\
26.1 & 0.2272 & & 36.8 & 0.1816 \\
54.2 & 0.3987 & & 73.0 & 0.3193 \\
121.2 & 0.6951 & & 153.9 & 0.5584 \\
233.5 & 1.0345 & & 278.0 & 0.8346 \\
388.2 & 1.3574 & & 438.3 & 1.1013 \\
640.1 & 1.7085 & & 693.6 & 1.4117 \\
967.0 & 2.0129 & & 1020.3 & 1.6951 \\
1341.5 & 2.2529 & & 1393.6 & 1.9298 \\
1741.0 & 2.4371 & & 1790.9 & 2.1158 \\
\hline
\end{tabular}

analysis and predictive purposes. The pure-component data are presented in Tables 2 and 3 for nitrogen and oxygen, respectively.

Binary equilibrium data were collected along three planes: constant $P-T$, constant $y-T$, and constant $y-P$ using the open system. These data are presented in Table 4. Data along the constant $y-T$ plane were also measured in the closed system. These are presented in
Table 3 Pure-gas adsorption of oxygen on Tosoh SA-500

\begin{tabular}{|ccccc|}
\hline \multicolumn{2}{|c}{$T=23^{\circ} \mathrm{C}$} & & \multicolumn{2}{c|}{$T=45^{\circ} \mathrm{C}$} \\
\cline { 1 - 2 } \cline { 5 - 5 } $\begin{array}{c}\text { Pressure } \\
(\mathrm{kPa})\end{array}$ & $\begin{array}{c}\text { Loading } \\
(\text { mol } / \mathrm{kg})\end{array}$ & & $\begin{array}{c}\text { Pressure } \\
(\mathrm{kPa})\end{array}$ & $\begin{array}{c}\text { Loading } \\
(\mathrm{mol} / \mathrm{kg})\end{array}$ \\
\hline 20.3 & 0.0407 & & 22.1 & 0.0281 \\
47.6 & 0.0941 & & 60.3 & 0.0767 \\
96.3 & 0.1806 & & 107.1 & 0.1344 \\
194.5 & 0.3557 & & 205.5 & 0.2484 \\
329.3 & 0.5603 & & 339.8 & 0.3954 \\
534.0 & 0.8336 & & 499.9 & 0.5553 \\
786.3 & 1.1154 & & 749.7 & 0.7773 \\
1080.1 & 1.3861 & & 1062.0 & 1.0157 \\
1390.2 & 1.6213 & & 1416.0 & 1.2443 \\
1766.1 & 1.8436 & & 1796.8 & 1.4499 \\
\hline
\end{tabular}

Table 5. The common base point is $23^{\circ} \mathrm{C}, 916 \mathrm{kPa}$, and $20 \% \mathrm{O}_{2}$ in the gas phase.

The uncertainties associated with the open system binary equilibrium data are indicated on Figures 6-12. These uncertainties were calculated based upon propagation of error analysis ${ }^{9}$. The uncertainty envelopes depict the largest expected random errors in the results; they do not correspond to actual uncertainties.

Table 4 Open system measurements for $\mathrm{N}_{2} / \mathrm{O}_{2}$ adsorption on Tosoh SA-500

\begin{tabular}{|c|c|c|c|c|c|c|c|}
\hline \multirow{2}{*}{$\begin{array}{l}T \\
\left({ }^{\circ} \mathrm{C}\right)\end{array}$} & \multirow{2}{*}{$\begin{array}{l}P \\
(\mathrm{kPa})\end{array}$} & \multicolumn{2}{|c|}{ Gas composition } & \multicolumn{3}{|c|}{ Loading (mol/kg) } & \multirow[b]{2}{*}{ Selectivity } \\
\hline & & $\mathrm{O}_{2}$ & $\mathrm{~N}_{2}$ & $\mathrm{O}_{2}$ & $\mathrm{~N}_{2}$ & Total & \\
\hline \multicolumn{8}{|c|}{ Constant $P-T$ plane } \\
\hline 23.2 & 921.1 & 0.0730 & 0.9270 & 0.0845 & 1.8648 & 1.9493 & 1.74 \\
\hline 23.3 & 915.0 & 0.1971 & 0.8029 & 0.1862 & 1.6596 & 1.8458 & 2.19 \\
\hline 23.2 & 913.5 & 0.2062 & 0.7938 & 0.2157 & 1.6947 & 1.9104 & 2.04 \\
\hline 23.3 & 911.5 & 0.2235 & 0.7765 & 0.2273 & 1.6415 & 1.8688 & 2.08 \\
\hline 23.3 & 919.0 & 0.3799 & 0.6201 & 0.3487 & 1.4632 & 1.8119 & 2.57 \\
\hline 23.3 & 916.3 & 0.5783 & 0.4217 & 0.5760 & 1.1390 & 1.7150 & 2.71 \\
\hline 23.3 & 909.4 & 0.5863 & 0.4137 & 0.6015 & 1.0921 & 1.6936 & 2.57 \\
\hline 23.3 & 915.0 & 0.7611 & 0.2389 & 0.7768 & 0.7513 & 1.5281 & 3.08 \\
\hline 23.2 & 912.8 & 0.8200 & 0.1800 & 0.8804 & 0.6379 & 1.5183 & 3.30 \\
\hline \multicolumn{8}{|c|}{ Constant $y-T$ plane } \\
\hline 23.3 & 22.8 & 0.1971 & 0.8029 & 0.0088 & 0.1681 & 0.1769 & 4.69 \\
\hline 23.3 & 42.2 & 0.2018 & 0.7982 & 0.0160 & 0.2762 & 0.2922 & 4.36 \\
\hline 23.3 & 101.0 & 0.2163 & 0.7837 & 0.0395 & 0.5029 & 0.5424 & 3.51 \\
\hline 23.4 & 206.8 & 0.2089 & 0.7911 & 0.0777 & 0.8329 & 0.9106 & 2.83 \\
\hline 23.3 & 508.9 & 0.1984 & 0.8016 & 0.1395 & 1.3096 & 1.3096 & 2.32 \\
\hline \multicolumn{8}{|c|}{ Constant $y-P$ plane } \\
\hline 0.4 & 912.1 & 0.2061 & 0.7939 & 0.3052 & 2.3677 & 2.6719 & 2.01 \\
\hline 0.4 & 913.5 & 0.2145 & 0.7855 & 0.2522 & 2.3507 & 2.6029 & 2.55 \\
\hline 44.6 & 909.4 & 0.1936 & 0.8064 & 0.1443 & 1.2744 & 1.4187 & 2.12 \\
\hline
\end{tabular}

Table 5 Closed system measurements for $\mathrm{N}_{2} / \mathrm{O}_{2}$ adsorption on Tosoh SA-500

\begin{tabular}{|c|c|c|c|c|c|c|c|}
\hline \multirow{2}{*}{$\begin{array}{l}{ }^{T} \\
\left({ }^{\circ} \mathrm{C}\right)\end{array}$} & \multirow{2}{*}{$\begin{array}{l}P \\
(\mathrm{kPa})\end{array}$} & \multicolumn{2}{|c|}{ Gas composition } & \multicolumn{3}{|c|}{ Loading $(\mathrm{mol} / \mathrm{kg})$} & \multirow[b]{2}{*}{ Selectivity } \\
\hline & & $\mathrm{O}_{2}$ & $\mathrm{~N}_{2}$ & $\mathrm{O}_{2}$ & $\mathrm{~N}_{2}$ & Total & \\
\hline \multicolumn{8}{|c|}{ Constant $y-T$ plane } \\
\hline 23.0 & 24.7 & 0.2053 & 0.7947 & 0.0085 & 0.1533 & 0.1618 & 4.66 \\
\hline 23.0 & 42.7 & 0.2053 & 0.7947 & 0.0159 & 0.2625 & 0.2784 & 4.26 \\
\hline 23.0 & 103.0 & 0.2069 & 0.7931 & 0.0369 & 0.4689 & 0.5358 & 3.53 \\
\hline 23.0 & 166.0 & 0.1984 & 0.8016 & 0.0533 & 0.6346 & 0.6879 & 2.95 \\
\hline 23.0 & 552.0 & 0.1995 & 0.8005 & 0.1338 & 1.3097 & 1.4435 & 2.44 \\
\hline 23.0 & 909.6 & 0.2223 & 0.7777 & 0.1914 & 1.8474 & 2.0388 & 2.76 \\
\hline
\end{tabular}


Table 6 Duplicate experimental results in open system

\begin{tabular}{|c|c|c|c|c|c|c|c|c|c|}
\hline \multirow{6}{*}{$\begin{array}{l}\text { Pressure }(\mathrm{kPa}) \\
\text { Temperature }\left({ }^{\circ} \mathrm{C}\right) \\
y\left(\mathrm{O}_{2}\right) \\
\mathrm{O}_{2} \text { Amount }(\mathrm{mol} / \mathrm{kg}) \\
\mathrm{N}_{2} \text { Amount }(\mathrm{mol} / \mathrm{kg})\end{array}$} & \multicolumn{2}{|c|}{ Set 1} & \multicolumn{2}{|c|}{ Set 2} & \multicolumn{2}{|c|}{ Set 3} & \multicolumn{3}{|c|}{ Set 4} \\
\hline & 909.5 & 916.4 & 42.2 & 44.7 & 912.2 & 913.6 & 913.6 & 915.0 & 911.5 \\
\hline & 23.3 & 23.3 & 23.3 & 23.2 & 0.4 & 0.4 & 23.2 & 23.3 & 23.3 \\
\hline & 0.5863 & 0.5783 & 0.2018 & 0.2142 & 0.2061 & 0.2145 & 0.2062 & 0.1971 & 0.2235 \\
\hline & 0.6015 & 0.5760 & 0.0160 & 0.0184 & 0.3052 & 0.2145 & 0.2157 & 0.1862 & 0.2273 \\
\hline & 1.0921 & 1.1390 & 0.2762 & 0.2850 & 2.3667 & 2.3507 & 1.6947 & 1.6596 & 1.6415 \\
\hline
\end{tabular}

Table 7 Virial isotherm constants for oxygen and nitrogen on Tosoh SA-500 ( $P$ in $\mathrm{kPa}, n$ in $\mathrm{mol} / \mathrm{kg})$

\begin{tabular}{|lrr|}
\hline & \multicolumn{1}{c|}{ Term 0} & \multicolumn{1}{c|}{ Term 1 } \\
\hline Oxygen & $12.69 \pm 0.14$ & $-1923 \pm 44$ \\
$K$ & & $112.9 \pm 39$ \\
$B$ & $-0.03858 \pm 0.13$ & \\
Nitrogen & & $-2958 \pm 95$ \\
$K$ & $14.54 \pm 0.31$ & $90.45 \pm 98$ \\
$B$ & $0.534 \pm 0.313$ & $-5.32 \pm 33$ \\
$C$ & $0.0081 \pm 0.109$ & \\
\hline
\end{tabular}

Reproducibility provides a better indication of actual uncertainties. It should be noted that it is not possible to exactly duplicate the gas phase properties, even in the open system, and thus some variation is expected. The repetition of experiments is summarized in Table 6. The standard deviations of partial oxygen and nitrogen loadings are 0.021 and $0.027 \mathrm{~mol} / \mathrm{kg}$, respectively, based on the three points around the base case conditions. Unfortunately, these small errors correspond to $10.1 \%$ and $1.6 \%$ of the measured values for oxygen and nitrogen, respectively. It is clear that the measurement of the less-sorbed component (oxygen in this case) is subject to relatively large errors.

\section{Correlation of pure-gas data}

The pure-gas data have been correlated using the virial isotherm model ${ }^{10}$.

$P=n^{*} e^{\left(K+B n+C n^{2}+D n^{3}+\cdots\right)}$

The first virial coefficient $(K)$ is related to the gas-solid interactions only, while the higher coefficients $(B, C, D$ etc.) also include the effects of gas-gas interactions. The virial coefficients can be approximated by infinite series in inverse temperature.

$K=k_{0}+\frac{k_{1}}{T}+\frac{k_{2}}{T^{2}}+\cdots$

$B=b_{0}+\frac{b_{1}}{T}+\frac{b_{2}}{T^{2}}+\cdots$

Although the constants in the higher-order virial coefficients $\left(b_{0}, c_{0}\right.$ etc. $)$ do not exist, they are included to compensate for the truncation of the infinite virial series after a finite number of terms. Equations (3)-(5) were used to regress all the isotherm data for a single gas simultaneously. One-step regression substantially improves the accuracy of the parameter regression, especially in the Henry's law region ${ }^{11}$.

The physical interpretations of the virial coefficients are strictly valid only for homogeneous adsorbents at low coverages. However, the virial model is very useful in representing pure-gas adsorption because of its mathematical flexibility. Parameter $t$-statistics were used to determine the number of inverse-temperature terms in Equations (4) and (5). The parameter values are listed in Table 7. As can be seen in Figures 4 and 5, the virial equation represents the isotherm data quite well.

It should be noted that, since the virial equation is "open-ended", there is no limit on the amount adsorbed as the pressure is increased. This can cause large errors if the virial equation is extrapolated beyond the range of the data. (This point is emphasized by the large uncertainties of the coefficients in Table 7.) However,

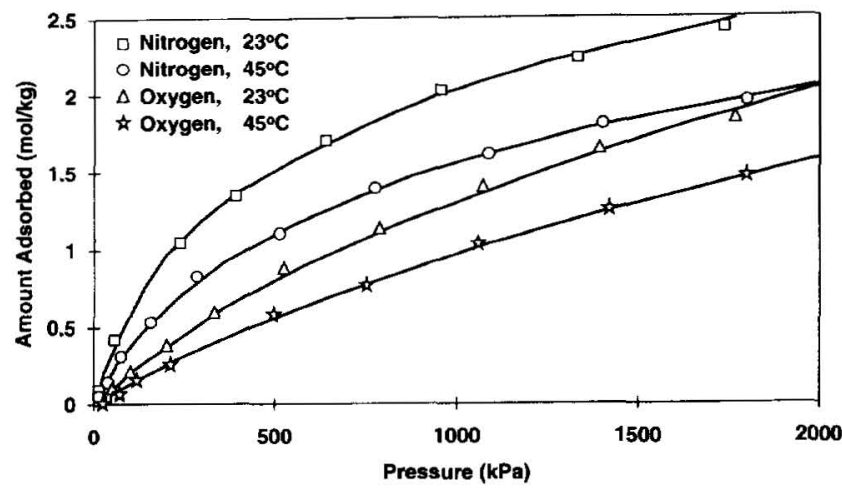

Figure 4 Adsorption of nitrogen and oxygen on 5A-zeolite. Points are data and lines are the correlation by the virial equation

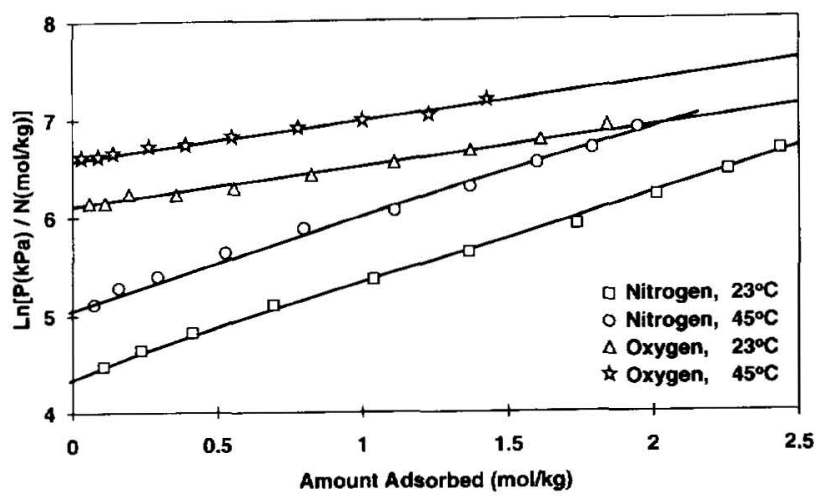

Figure 5 Adsorption (logarithm of $P(n)$ of nitrogen and oxygen on $5 \mathrm{~A}$-zeolite. Points are data and lines are the correlation by the virial equation 
within the temperature and pressure limits of the data, we have found the virial equation to be flexible, thermodynamically consistent, and a reliable way to calculate the Henry's law constant with good accuracy. Additionally, the Henry's law constants can be directly determined from data plotted in the virial domain in Figure 5 without any curve-fitting, as suggested by Barrer ${ }^{12}$.

The virial representation of the pure-gas isotherms forms the basis of the $\mathrm{IAST}^{7}$ predictions, and the thermodynamic consistency analysis presented later in this paper.

\section{Discussion of data trends}

Binary gas adsorption involves three degrees of freedom: pressure, temperature and gas composition. All three variations are important to the design of air separation units and have been studied in this work.

\section{Effect of gas composition}

Figures 6,7 and 8 provide different views of the adsorption as a function of gas composition at the base temperature and pressure. These figures also present the maximum uncertainty of the experimental measurement and the IAST predictions. The IAST predictions serve as a thermodynamic test of the data consistency and as a potential method to predict the mixed-gas data.

Figure 6 presents the total and partial amounts adsorbed. The IAST method somewhat under-predicts the total amount adsorbed, but the significance is questionable since the predictions are within the reproducibility of the data $(3-5 \%)$. It should be noted that the IAST prediction of the total loading is well within the maximum uncertainty of the data. IAST provides a good prediction of the adsorption of nitrogen, but a relatively poor description of the adsorption of oxygen. In general, IAST provides a good prediction of the strongly adsorbed component, but may not provide a good prediction of the weakly adsorbed component.

The $x-y$ diagram (Figure 7), although commonly used to display binary adsorption behavior, does not have enough sensitivity to discriminate between data and models at the accuracy levels necessary for plant design. The selectivity is a much more sensitive indicator of phase behavior, as indicated in Figure 8. The selectivity is defined as follows:

$\alpha_{\mathrm{N}_{2} / \mathrm{O}_{2}}=\frac{n_{\mathrm{N}_{2}} / y_{\mathrm{N}_{2}}}{n_{\mathrm{O}_{2}} / y_{\mathrm{O}_{2}}}$

The $\mathrm{N}_{2} / \mathrm{O}_{2}$ selectivity increases from about 1.8 at the nitrogen-rich end to well in excess of 3 for compositions rich in oxygen. The IAST predictions are clearly too optimistic since they are outside the maximum errors of the data.

IAST serves a useful purpose in analyzing the thermodynamic consistency of the data. Thermodynamic consistency requires that the IAST predictions

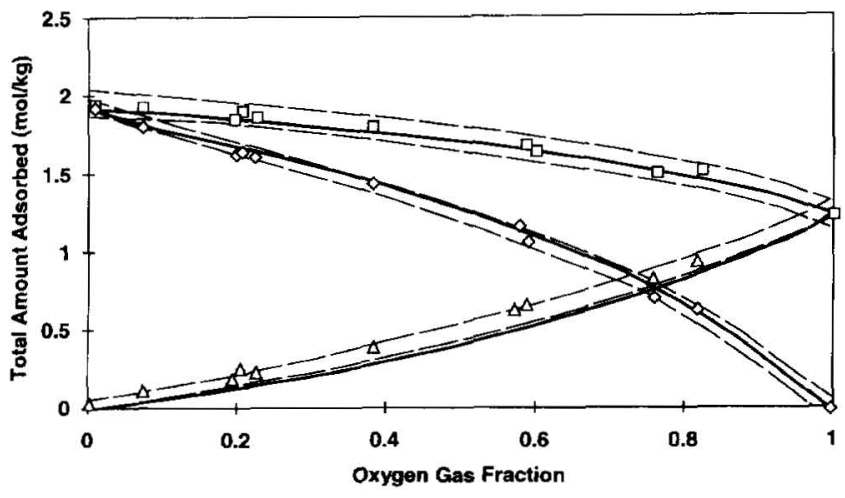

Figure 6 Total and partial amounts of $\mathrm{N}_{2}$ and $\mathrm{O}_{2}$ adsorbed. Gas composition variation at $915 \mathrm{kPa}$ and $23.3^{\circ} \mathrm{C}$. Points are the experimental data, full lines are the IAST prediction, and the dashed lines depict the maximum uncertainty in the measured data

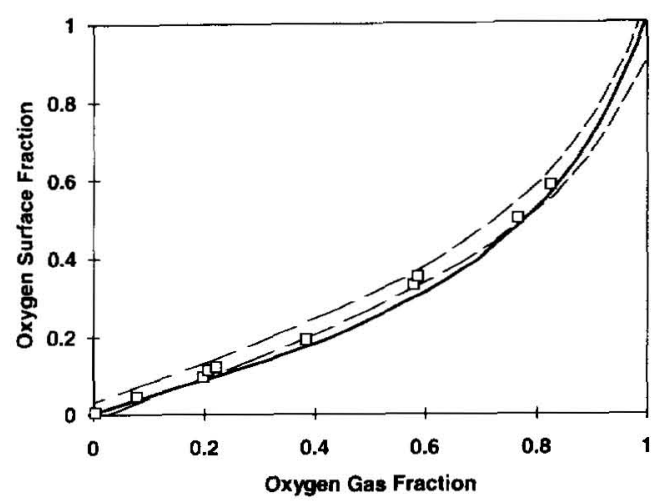

Figure 7 Adsorbed phase versus gas phase composition at $915 \mathrm{kPa}$ and $23.3^{\circ} \mathrm{C}$. Points are the experimental data, full lines are the IAST prediction, and the dashed lines depict the maximum uncertainty in the measured data

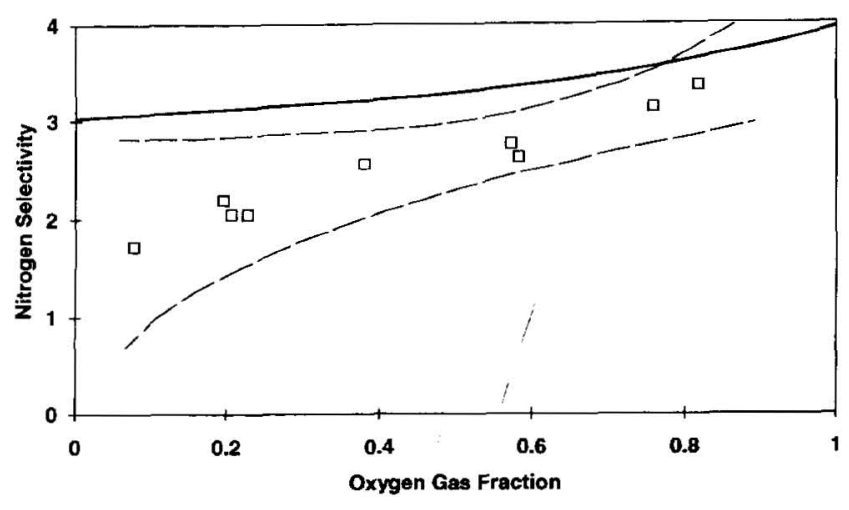

Figure $8 \quad \mathrm{~N}_{2} / \mathrm{O}_{2}$ selectivity at $915 \mathrm{kPa}$ and $23.3^{\circ} \mathrm{C}$. Points are the experimental data, full lines are the IAST prediction, and the dashed lines depict the maximum uncertainty in the measured data

in Figure 8 cross the experimental data ${ }^{13}$. The trend of the data suggests that this cross will occur at high oxygen concentrations, but we have not measured data at high enough oxygen concentrations to confirm this.

\section{Effect of pressure}

The effect of pressure was studied at $23^{\circ} \mathrm{C}$ and about $21 \%$ oxygen. Figure 9 presents total and partial oxygen 


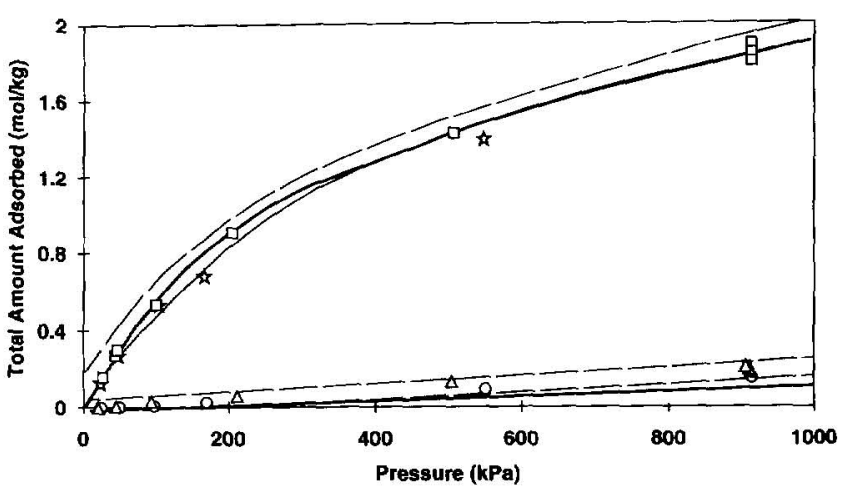

Figure 9 Total and partial amounts of $\mathrm{N}_{2}$ and $\mathrm{O}_{2}$ adsorbed Pressure variation at $23^{\circ} \mathrm{C}$ and $20 \% \mathrm{O}_{2}$ in the gas phase. Points are the experimental data, full lines are the IAST prediction, and the dashed lines depict the maximum uncertainty in the measured data

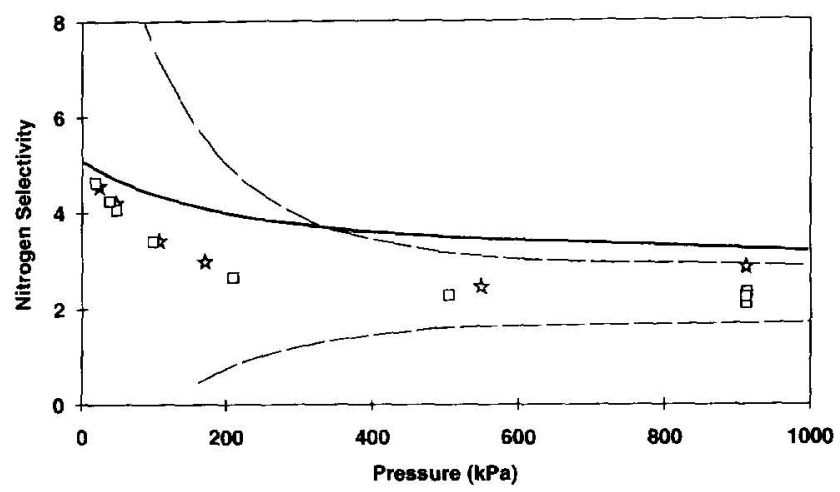

Figure $10 \quad \mathrm{~N}_{2} / \mathrm{O}_{2}$ selectivity at $23^{\circ} \mathrm{C}$ and $20 \% \quad \mathrm{O}_{2}$ in the gas phase. Points are the experimental data, full lines are the IAST prediction, and the dashed lines depict the maximum uncertainty in the measured data

loadings as a function of pressure; nitrogen loading is not shown for clarity since it is close to the total. The data from the closed and open systems are in good agreement.

The effect of pressure on selectivity is depicted in Figure 10. As required by thermodynamic consistency, IAST and the binary data approach the same limiting selectivity of 5.2 at zero pressure; this limiting selectivity is the ratio of the Henry's law constants of $\mathrm{N}_{2}$ and $\mathrm{O}_{2}$. The IAST method predicts a far weaker drop in the selectivity than is experimentally observed. As with the composition variation, the selectivity diagram is an effective, sensitive way to present the trend of the phase behavior.

Figure 10 presents the maximum uncertainty in the measured selectivity, which approaches infinity at zero pressure. The large uncertainty in the selectivity at low pressures (and at the pure-component limits) is inevitable in these experiments where the primary properties are the partial amounts adsorbed. A different experimental technique could be designed to measure selectivity directly, but then the uncertainty in the total amount adsorbed would become unacceptably large at low pressures and at the pure-component limit. On the positive side though, we note that it is not necessary to

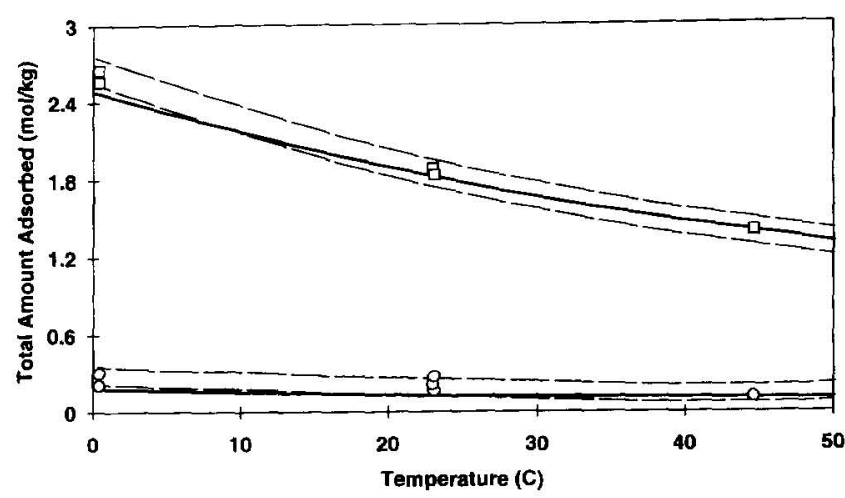

Figure 11 Total and partial amounts of $\mathrm{N}_{2}$ and $\mathrm{O}_{2}$ adsorbed Temperature variation at $913 \mathrm{kPa}$ and $20 \% \mathrm{O}_{2}$ in the gas phase. Points are the experimental data, full lines are the IAST prediction, and the dashed lines depict the maximum uncertainty in the measured data

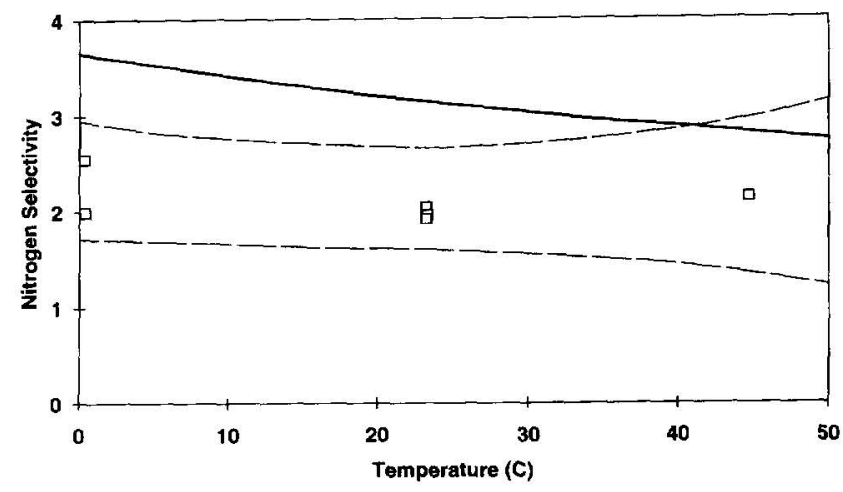

Figure $12 \quad \mathrm{~N}_{2} / \mathrm{O}_{2}$ selectivity at $913 \mathrm{kPa}$ and $20 \% \mathrm{O}_{2}$ in the gas phase. Points are the experimental data, full lines are the IAST prediction, and the dashed lines depict the maximum uncertainty in the measured data

measure multicomponent data at very low pressures since the limiting behavior will approach Henry's law, which only requires pure-component measurements.

\section{Effect of temperature}

The impact of temperature is seldom studied in the literature, but there are significant temperature variations in adsorption processes due to the heat of adsorption ${ }^{2}$. As can be seen in Figure 11, a relatively small temperature change $\left(20^{\circ} \mathrm{C}\right)$ will cause the total amount adsorbed to change by $25 \%$. At the conditions studied $\left(912 \mathrm{kPa}\right.$ and $\left.y\left(\mathrm{O}_{2}\right)=0.207\right)$, the effect of temperature on selectivity is small, as indicated in Figure 12. However, we note that IAST provides a poor prediction of the selectivity.

\section{Thermodynamic consistency analysis}

As discussed above, multicomponent adsorption equilibrium measurements are extremely complicated and therefore more prone to error than equilibrium measurements of bulk phases. Thus, there is good reason to be skeptical about the accuracy of the derived results. 
Fortunately, thermodynamic principles provide relations between the adsorbed phases that can be used to access the results. It should be noted that the thermodynamic tests only provide an internal consistency check among a set of pure and multicomponent data. They do not assure accuracy. However, consistency of a set of data increases confidence that the data are accurate.

As outlined by Talu and Myers ${ }^{13}$, there are numerous tests of thermodynamic consistency. We employed the following:

(1) At fixed temperature and pressure, the total amount adsorbed must equal the pure-component values at the composition end points. As Figure 6 indicates, this test is satisfied.

(2) At fixed temperature and pressure, the $x-y$ and selectivity curves of all thermodynamically consistent models must cross the experimental curves at least once. As discussed above, Figure 8 suggests that this test is satisfied.

(3) The selectivity must approach the value determined by the Henry's law constants at zero pressure. Figure 10 indicates that this test is satisfied.

(4) The spreading pressure is a state function, and thus the spreading pressure difference between any two conditions must be independent of the path between the two conditions. The Gibbs adsorption equation has been used to calculate the change in spreading pressure at constant pressure.

$\mathrm{d}\left(\frac{\pi A}{R T}\right)=\sum_{i} n_{i} \mathrm{~d}\left\{\ln \left(P y_{i}\right)\right\} \quad$ (constant $\left.T\right)$

The integrations are performed over the closed paths illustrated in Figure 13; these are ABCDEA, ABCFA, and $\mathrm{FCDEF}^{14}$. The integrations over the line $\mathrm{AFE}$ are zero since the change in pressure (and hence the spreading pressure) is zero. The results of integration over these paths are summarized in Table 8. The data are consistent as the relative differences are about $6 \%$ among the three paths.

Given large possible errors indicated by the propagation of error analysis, occasional "fliers" are likely. We found the last test to be extremely useful for screening

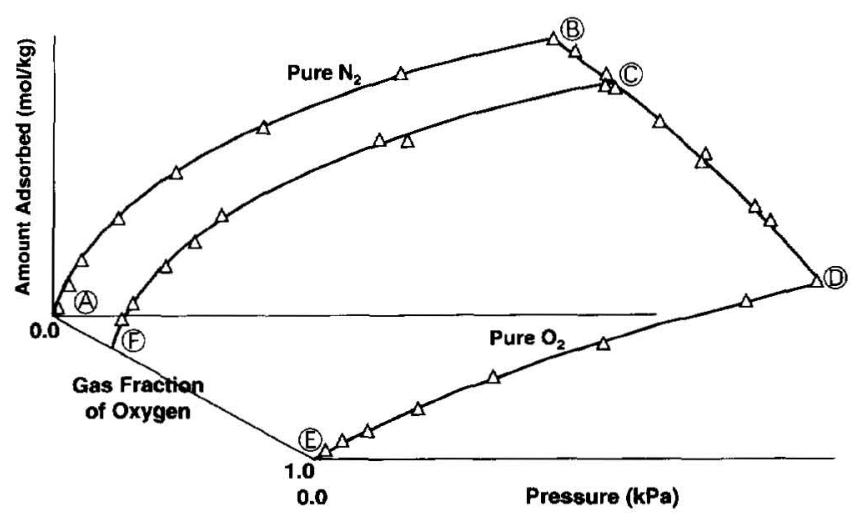

Figure 13 Schematic diagram of spreading pressure integrations
Table 8 Integrations for thermodynamic consistency over closed paths shown in Figure 13

\begin{tabular}{|c|c|c|c|c|c|}
\hline & \multicolumn{2}{|c|}{ End conditions } & \multicolumn{3}{|c|}{ Integrals $(\mathrm{mol} / \mathrm{kg})$} \\
\hline & $P(\mathrm{kPa})$ & $y\left(\mathrm{O}_{2}\right)$ & $\mathrm{O}_{2}$ & $\mathrm{~N}_{2}$ & Total \\
\hline \multicolumn{6}{|c|}{ Section $A-B$ : pure nitrogen isotherm } \\
\hline \multirow[t]{2}{*}{ Start } & 0.0 & 0.0 & 0.0 & 0.0 & 0.0 \\
\hline & 914.8 & 0.0 & 0.0 & 3.486 & 3.486 \\
\hline \multicolumn{6}{|c|}{ Section B-C: constant $P$ and $T$ binary data } \\
\hline \multirow[t]{3}{*}{ Start } & 914.8 & 0.0 & 0.0 & 0.0 & 0.0 \\
\hline & 921.2 & 0.073 & 0.080 & 0.131 & -0.053 \\
\hline & 915.0 & 0.197 & 0.209 & -0.396 & -0.187 \\
\hline \multicolumn{6}{|c|}{ Section $\mathrm{C}-\mathrm{D}$ : constant $P$ and $T$ binary data } \\
\hline \multirow[t]{9}{*}{ Start } & 915.0 & 0.197 & 0.0 & 0.0 & 0.0 \\
\hline & 913.6 & 0.206 & 0.009 & -0.022 & -0.013 \\
\hline & 912.2 & 0.224 & 0.026 & -0.061 & -0.035 \\
\hline & 919.1 & 0.380 & 0.171 & -0.397 & -0.226 \\
\hline & 916.4 & 0.578 & 0.360 & -0.903 & -0.544 \\
\hline & 909.5 & 0.586 & 0.364 & -0.933 & -0.570 \\
\hline & 915.0 & 0.761 & 0.547 & -1.433 & -0.886 \\
\hline & 912.9 & 0.820 & 0.606 & -1.632 & -1.025 \\
\hline & 914.8 & 1.000 & 0.815 & -2.446 & -1.630 \\
\hline \multicolumn{6}{|c|}{ Section D-E: pure oxygen isotherm } \\
\hline \multirow[t]{2}{*}{ Start } & 914.0 & 1.0 & 0.0 & 0.0 & 0.0 \\
\hline & 0.0 & 1.0 & -1.482 & 0.0 & -1.482 \\
\hline \multicolumn{6}{|c|}{ Section $\mathrm{F}-\mathrm{C}$ : constant $y$ and $T$ binary data } \\
\hline \multirow[t]{8}{*}{ Start } & 0.0 & - & - & - & 0.0 \\
\hline & 22.8 & 0.197 & 0.009 & 0.180 & 0.189 \\
\hline & 42.2 & 0.202 & 0.017 & 0.314 & 0.331 \\
\hline & 44.7 & 0.214 & 0.019 & 0.326 & 0.344 \\
\hline & 101.0 & 0.216 & 0.042 & 0.644 & 0.686 \\
\hline & 206.9 & 0.209 & 0.078 & 1.128 & 1.206 \\
\hline & 508.9 & 0.198 & 0.165 & 2.141 & 2.306 \\
\hline & 915.0 & 0.197 & 0.261 & 3.015 & 3.276 \\
\hline
\end{tabular}

Totals

Path $\mathrm{ABCDE}=\mathrm{A}-\mathrm{B}+\mathrm{B}-\mathrm{C}+\mathrm{C}-\mathrm{D}+\mathrm{D}-\mathrm{E}$ $=3.486-0.187-1.630-1.482=0.186$

Error $=5.3 \%$ of maximum

Path $\mathrm{ABCF}=\mathrm{A}-\mathrm{B}+\mathrm{B}-\mathrm{C}-\mathrm{F}-\mathrm{C}$ $=3.486-0.187-3.287=0.023$

Error $=0.7 \%$ of maximum

Path FCDE $=\mathrm{F}-\mathrm{C}+\mathrm{C}-\mathrm{D}+\mathrm{D}-\mathrm{E}$ $=3.276-1.630-1.482=0.164$

Error $=5.0 \%$ of maximum

individual points. On the basis of thermodynamic consistency analysis, we conclude that the set of data presented here is internally consistent.

\section{Thermodynamic data analysis}

An additional benefit of the spreading pressure integrations is that they provide a thermodynamic analysis of the system. The experimental values of the excess Gibbs free energy can be calculated from the spreading pressure by the following relations ${ }^{14}$.

$\gamma_{i}=\frac{P y_{i} \phi_{i}}{P_{i}^{0} \phi_{i}^{0} x_{i}}$

$\frac{G^{e x}}{R T}=\sum_{i} x_{i} \ln \gamma_{i}$

The activity coefficients at the binary data points are presented in Table 9. The variation of the activity 
Table 9 Surface phase activity coefficients and excess Gibbs free energy calculated from experimental data

\begin{tabular}{|lccccc|}
\hline$T\left({ }^{\circ} \mathrm{C}\right)$ & $P(\mathrm{kPa})$ & $y\left(\mathrm{O}_{2}\right)$ & $\gamma\left(\mathrm{O}_{2}\right)$ & $\gamma\left(\mathrm{N}_{2}\right)$ & $G^{e x} / R T$ \\
\hline \multicolumn{5}{c}{ Constant temperature and pressure } \\
23.2 & 921.2 & 0.073 & 0.572 & 1.013 & -0.012 \\
23.3 & 915.0 & 0.197 & 0.699 & 0.997 & -0.039 \\
23.2 & 913.6 & 0.206 & 0.657 & 1.008 & -0.040 \\
23.3 & 912.2 & 0.224 & 0.665 & 1.003 & -0.047 \\
23.3 & 919.1 & 0.380 & 0.783 & 0.974 & -0.068 \\
23.3 & 916.4 & 0.578 & 0.794 & 0.973 & -0.096 \\
23.3 & 909.5 & 0.586 & 0.766 & 0.993 & -0.100 \\
23.3 & 915.0 & 0.763 & 0.841 & 0.949 & -0.114 \\
23.2 & 912.9 & 0.820 & 0.862 & 0.926 & -0.119 \\
Constant & composition and temperature & & \\
23.3 & 22.8 & 0.197 & 0.942 & 0.989 & -0.013 \\
23.3 & 42.2 & 0.202 & 0.907 & 0.993 & -0.012 \\
23.2 & 44.7 & 0.214 & 0.884 & 0.999 & -0.009 \\
23.3 & 101.0 & 0.216 & 0.797 & 1.011 & -0.007 \\
23.4 & 206.9 & 0.209 & 0.705 & 1.015 & -0.016 \\
23.3 & 508.9 & 0.198 & 0.656 & 0.986 & -0.053 \\
23.3 & 912.2 & 0.224 & 0.665 & 1.003 & -0.047 \\
23.2 & 913.6 & 0.206 & 0.657 & 1.008 & -0.040 \\
23.3 & 915.0 & 0.197 & 0.699 & 0.997 & -0.039 \\
\hline
\end{tabular}

coefficients with composition is shown in Figure 14. The system exhibits negative deviations from ideality. Negative deviations are generally linked to heterogeneity of the adsorbent ${ }^{15}$.

Figure 14 indicates that the system is strongly nonideal; the infinite dilution activity coefficient of oxygen is about 0.5. Figures 6 and 7 do not give an indication of the strong nonideality, but Figure 8 certainly does. This is another reason why selectivity diagrams are a preferred way to present adsorption equilibrium data.

Figure 14 is highly asymmetric, but this is an artificial result since the gas phase composition has been used in the abscissa. As shown in Figure 15, the excess Gibbs free energy is close to symmetric with respect to the surface composition.

The activity coefficients and excess Gibbs free energy are shown as a function of spreading pressure in Figure 16. The temperature and gas composition are fixed at $23^{\circ} \mathrm{C}$ and $20.7 \% \quad \mathrm{O}_{2}$, respectively. $G^{e x}$ approaches zero at zero spreading pressure, which is a

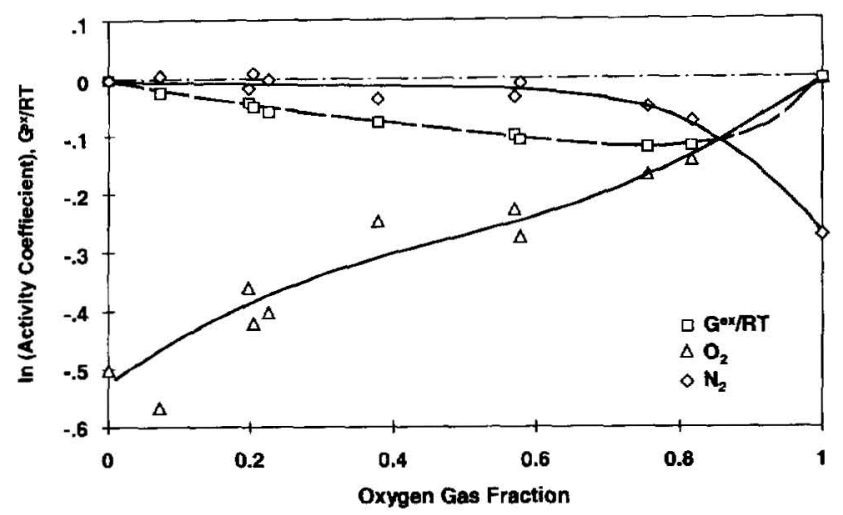

Figure 14 Calculated nonideality of the $\mathrm{N}_{2} / \mathrm{O}_{2}$ adsorbed phase at $23^{\circ} \mathrm{C}$ and $915 \mathrm{kPa}$ as a function of gas phase composition. The lines are a curve-fit of the data unique feature of surface phases. This behavior makes it thermodynamically inconsistent to use liquid models (such as the Wilson equation) for the surface phase. It is also clear from Figure 16 that the derivative of $G^{e x}$ with spreading pressure is not zero at the origin. In other words, the excess area of mixing is finite although $G^{e x}$ is zero. The reasons for this phenomena are thoroughly discussed by Talu et al. ${ }^{16}$.

\section{Conclusions}

The techniques presented in this paper provide methods to generate and analyze multicomponent adsorption equilibrium data. Both the open and closed methods were found to provide reasonably accurate data if care was taken in equipment design and data collection. Unfortunately, relatively high uncertainties in the loading of the less strongly adsorbed component ( $\sim 5-20 \%)$ appear to be unavoidable. This is particularly true at low pressures and at both composition limits. We have found the thermodynamic consistency tests described above to be helpful in establishing the reliability of the data, and thus increasing confidence in its accuracy.

Using data from both of these methods, we have produced a complete, evaluated set of data for a system

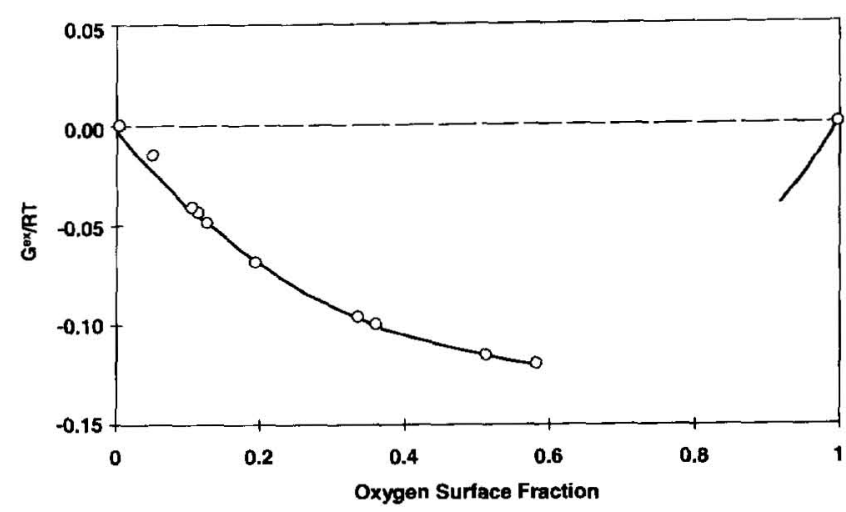

Figure 15 Calculated nonideality of the $\mathrm{N}_{2} / \mathrm{O}_{2}$ adsorbed phase at $23^{\circ} \mathrm{C}$ and $915 \mathrm{kPa}$ as a function of surface phase composition. The line is a curve-fit of the data

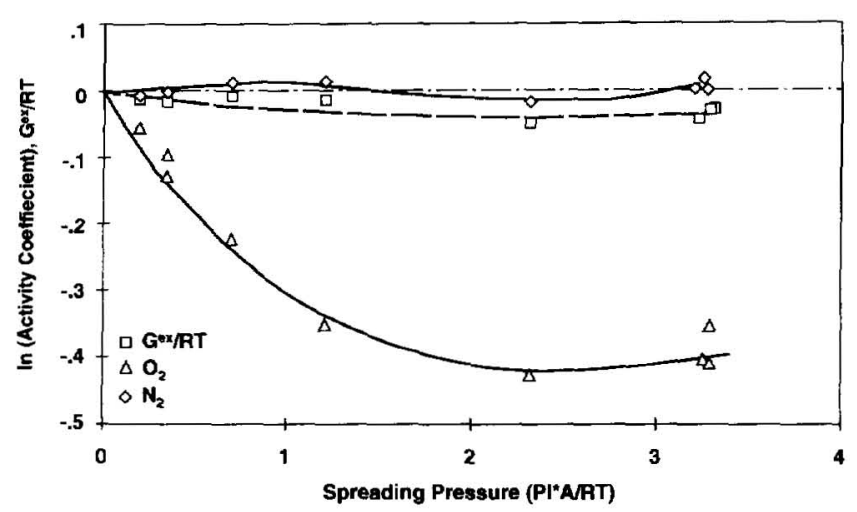

Figure 16 Calculated nonideality of the $\mathrm{N}_{2} / \mathrm{O}_{2}$ adsorbed phase at $23^{\circ} \mathrm{C}$ and $20 \% \mathrm{O}_{2}$ in the gas phase as a function of spreading pressure. The lines are a curve-fit of the data 
of industrial interest: $\mathrm{N}_{2} / \mathrm{O}_{2}$ adsorption on 5A-zeolite. We are confident in the accuracy of these data based on thermodynamic consistency tests, reproducibility studies and the agreement between the data from two different systems. The data indicate a significant nonideality, since IAST does not provide a quantitatively accurate description of the data.

\section{References}

Keller, G.E. AIChE Monograph Ser No 17 (1987) 831

2 Sircar, S. Pressure swing adsorption research needs by industry Fundamentals of Adsorption, Proceedings of the Engineering Foundation Conference, Soonthofen, Germany (1991) 815

3 Hartzog, D.G. and Sircar, S. Sensitivity of PSA process performance to input variables $A I C h E$ Annual Meeting St. Louis, MO (1993)

4 Danner, R.P. and Wenzel, L.A. Adsorption of carbon monoxidenitrogen, carbon monoxide-oxygen, and oxygen-nitrogen on synthetic zeolites AIChE J (1969) 15(4) 515

5 Miller, G.W., Knaebel, K.S. and Ikels, K. Equilibria of nitrogen, oxygen, argon, and air in molecular sieve 5A AIChE J (1987) 33(2) 194
6 Sorrel, G.A., Granville, W.H. and Daly, W.O. Adsorption equilibria for oxygen and nitrogen gas mixtures on $5 \mathrm{~A}$ molecular sieves Chem Eng Sci (1983) 38(9) 1517

7 Myers, A.L. and Prausnitz, J.M. Thermodynamics of mixed-gas adsorption AIChE J (1965) 11(1) 121

8 Prausnitz, J.M., Lichtenthaler, R.N. and Gomes de Azevedo, E. Molecular Thermodynamics of Fluid Phase Equilibria 2nd Edn, Prentice-Hall, Englewood Cliffs, NJ (1985)

9 Jenson, V.G. and Jeffreys, G.V. Mathematical Methods in Chemical Engineering Academic Press, London (1977)

10 Ross, S. and Olivier, J.P. On Physical Adsorption Interscience, New York (1964)

11 Talu, O. and Hayhurst, D.T. Isosteric heat of adsorption by the virial isotherm equation AIChE Annual Meeting San Francisco (November 1989)

12 Barrer, R.M. Zeolites and Clay Minerals as Sorbents and Molecular Sieves Academic Press, New York (1978)

13 Talu, O. and Myers, A.L. Rigorous treatment of gas adsorption AIChE J (1988) 34(11) 1887

14 Talu, $\mathbf{O}$. and Zwiebel, I. Multicomponent adsorption equilibria of nonideal mixtures AIChE $J$ (1986) 32(8) 1263

15 Valenzuela, D.P., Myers, A.L., Talu, O. and Zwiebel, I. Adsorption of gas mixtures: effect of energetic heterogeneity $A I C h E J$ (1988) 34(3) 397

16 Talu, O., Li, J. and Myers, A.L. Activity coefficients of adsorbed mixtures Adsorption in press 